Ssciendo

\title{
Intentionality, Knowledge and Formal Objects
}

Kevin Mulligan

Université de Genéve

Disputatio Vol. 2, No. 23

November 2007

DOI: $10.2478 /$ disp-2007-0010

ISSN: 0873-626X 


\title{
Intentionality, knowledge and formal objects
}

\author{
Kevin Mulligan \\ Université de Genéve
}

\begin{abstract}
What is the relation between the intentionality of states and attitudes which can miss their mark, such as belief and desire, and the intentionality of acts, states and attitudes which cannot miss their mark, such as the different types of knowledge and simple seeing? Two theories of the first type of intentionality, the theory of correctness conditions and the theory of satisfaction conditions, are compared. It is argued that knowledge always involves knowledge of formal objects such as facts and values, that emotions are reactions to (apparently) known values and that beliefs are reactions to known or apparently known facts or to the objects of relational states.
\end{abstract}

\section{Intentionality ${ }^{1}$}

Any philosophy of intentionality, of the property peculiar to mental acts, states and activities of being 'directed' towards or about something, should contain many chapters. It should provide an account of the different mental acts, states and activities. It should provide an analysis of the relations and other ties hiding behind the metaphor of directedness. And it should provide an account of the sorts of things mental acts, states and activities are directed towards. A philosophy of intentionality should, further, tell us about the intentionality of all the main types of mental states, acts and activities. It should tell us, at the very least, about the intentionality of

acquaintance, admiration, attention, belief that, belief in, certainty, choice, deliberation, desire, doubt, expectation, hate, hope, imagination, judge-

${ }^{1}$ An earlier version of this paper appeared in an electronic Festschrift: Hommage à Wlodek. Philosophical Papers Dedicated to Wlodek Rabinowicz. Ed. T. RønnowRasmussen, B. Petersson, J. Josefsson \& D. Egonsson, $2007<$ http://www.fil. lu.se/hommageawlodek $>$.

Disputatio, Vol. II, No. 23, November 2007 (special issue) 
ment, knowledge, love, meaning that $\mathrm{p}$, memory, perception, preference, regret, shame, sympathy, striving, supposition, time-consciousness, trust, uncertainty, understanding, vision, willing and wishes

and not limit itself to, say, the intentionality of belief and desire. A philosophy of intentionality should provide an account of the difference between collective or shared intentionality, for example that of shared shame or shared certainties, and solitary intentionality, such as that of judgement. It should also tell us how the intentionality of different acts and states hang together, how, for example, the intentionality of emotions is related to the intentionality of perception and belief, how the intentionality of visual imagination is related to that of vision, a desideratum which cannot be met by philosophies of intentionality which consider only a handful of types of mental states and acts.

Some types of acts, activities and states are such that tokens of the type may miss their mark, go wrong or be unsuccessful. Memory misleads, suspicions are unfounded, beliefs turn out to be incorrect. Mental states which can go wrong contrast strikingly with types of states and acts such as knowledge, seeing and perception which cannot miss their mark. In what follows, I explore the relations between states and acts which can go wrong, on the one hand, and knowledge, seeing and perception, on the other hand. I consider two accounts of states and acts which can miss their mark, the theory of satisfaction conditions and the theory of correctness conditions (\$2). I then consider two objections to the theory of correctness conditions: correctness conditions are not truth-evaluable and one central type of correctness condition, for judgement and belief, is superfluous. I then argue that one plausible account of the intentionality of knowledge gives us some reason to reject the objections to the very idea of correctness conditions. The preferred account comes in two parts, an account of knowledge and its relation to objects and facts $(\S 3)$ and an account of knowledge of value (§4). I then argue that the intentionality of knowledge, understood in the preferred way, is more fundamental than the intentionality of acts and states which can go wrong (\$5).

\section{Correctness conditions vs. satisfaction conditions}

Consider those states and acts which may miss their mark. One account of what it is for states and acts to miss their target, is the theory of satisfaction conditions. This theory is part of an account of 
what it is for such states and acts to enjoy the property of intentionality. A simplified version of Searle's account of the satisfaction conditions for belief is that a belief that $p$ is satisfied only if $p$. Similarly, a simplified version of the satisfaction condition for $\mathrm{x}$ 's desire to $\mathrm{F}$ is:

$$
\text { Cause (x's desire that } F x, F x)^{2}
$$

Another account of what it is for states and acts to miss their mark is the theory of correctness conditions, a theory associated with Husserl. In the following table, the sentences on the right express putative correctness conditions for the psychological reports on the left:

\begin{tabular}{|c|c|}
\hline$x$ desires to F & $x$ ought to F ('Tunsollen') \\
\hline$x$ wishes that $p$ & $\begin{array}{l}\text { It ought to be the case that } \mathrm{p} \text { ('Sein- } \\
\text { sollen') }\end{array}$ \\
\hline$x$ values $y$ & $y$ is valuable \\
\hline$x$ admires $y$ & $y$ is admirable \\
\hline$x$ fears $y$ & $y$ is dangerous \\
\hline$x$ 'values' that $p$ & $\begin{array}{l}\text { That } p \text { is valuable, is a 'Wertver- } \\
\text { halt' }\end{array}$ \\
\hline$x$ regrets that $p$ & It is regrettable that $p$ \\
\hline$x$ is ashamed that $p$ & It is shameful that $p$ \\
\hline$x$ prefers $y$ to $z$ & $y$ is better than $z$ \\
\hline$x$ judges (believes) that $p$ & $\begin{array}{l}\text { The state of affairs that } p \text { obtains } \\
\text { The proposition that } p \text { is true }\end{array}$ \\
\hline$x$ conjectures that $p$ & It is probable that $p$ \\
\hline $\begin{array}{r}x \text { has an interrogative attitude } \\
\text { toward p }\end{array}$ & It is questionable whether $\mathrm{p}$ \\
\hline$x$ doubts whether $p$ & It is doubtful whether $p$ \\
\hline$x$ is certain that $p$ & It is certain that $p$ \\
\hline
\end{tabular}

${ }^{2}$ Cf. Searle 1983: 13 (belief), ch. 3 (desire). 
Kenny distinguishes between the material and formal objects of mental attitudes and argues that emotional and other attitudes have formal objects. ${ }^{3}$ He attributes to the medieval schoolmen the view that the formal object of fear is a future evil, of envy another's good. Similarly, one might say that propositions, states of affairs, truth and obtaining, values, norms and probabilities are the formal objects of different attitudes, states and acts. Then fear will have, for example, a dog as its material or proper object and a future evil or disvalue as its formal object. A conjecture that the dog will attack has as its material object the dog and the probability that it will attack as its formal object. One unfortunate but perhaps harmless feature of this terminology is that it runs together a narrow and a wide sense of 'object'. In the narrow sense, propositions and states of affairs are the formal objects of judgements and beliefs. Truth, obtaining, oughtness and value, on the other hand, are not formal objects, in the narrow sense of the word, of judgements, beliefs, desires and emotions.

It is a peculiarity of judgement (and of belief and convictions) that it seems to have two correctness conditions: the truth of propositions and the obtaining of states of affairs or the existence of facts. We shall return to this feature of judgement and belief.

How should the theory of correctness conditions be formulated? Presumably, as follows:

$\mathrm{x}$ desires to $\mathrm{F} \rightarrow$ ( $\mathrm{x}$ correctly (rightly) desires to $\mathrm{F}$ iff $\mathrm{x}$ ought to $\mathrm{F}$ ).

$\mathrm{x}$ wishes that $\mathrm{p} \rightarrow$ ( $\mathrm{x}$ correctly (rightly) wishes that $\mathrm{p}$ iff it ought to be the case that $\mathrm{p})$.

$\mathrm{x}$ conjectures that $\mathrm{p} \rightarrow$ ( $\mathrm{x}$ correctly (rightly) conjectures that $\mathrm{p}$ iff it is probable that $\mathrm{p}$ ).

And so on. But the theory of correctness conditions contains an extra type of claim, an explanatory claim:

If $\mathrm{x}$ correctly judges that $\mathrm{p}$, then ( $\mathrm{x}$ correctly judges that $\mathrm{p}$ because the state of affairs that $p$ obtains).

If $\mathrm{x}$ correctly judges that $\mathrm{p}$, then ( $\mathrm{x}$ correctly judges that $\mathrm{p}$ because the proposition that $\mathrm{p}$ is true).

If $\mathrm{x}$ correctly conjectures that $\mathrm{p}$, then ( $\mathrm{x}$ correctly conjectures that $\mathrm{p}$ because it is probable that $\mathrm{p}$ ).

\footnotetext{
${ }^{3}$ Kenny 1963, ch. 9. On the formal objects of emotions, cf. Teroni 2007.
} 
And so on.

What are the relations between correctness and satisfaction conditions?

Firstly, 'correct' ('right', 'richtig'), unlike 'satisfied', is obviously a normative predicate. Correctness (right) and incorrectness (wrong) constitute one of the main families of normative or nontheoretical predicates along with, for example, the family of deontic predicates and the family of value predicates, thin ('valuable') and thick ('cool', 'unjust').

Secondly, the fit of satisfaction is either mind-to-world fit (belief) or world-to-mind fit (desire). Whatever this amounts to it is presumably compatible with the claim that if a state or attitude is satisfied, then it is satisfied because its satisfaction condition holds. If there is a fit of correctness, it is always a mind-to-world fit in the following sense: attitudes, states and acts are correct, if they are correct, because the world is the way the correctness conditions say it is.

Thirdly, correctness conditions, unlike satisfaction conditions, refer to formal objects (propositions, states of affairs) or are dominated by formal predicates or functors (truth, obtaining, value, ought, probability). ${ }^{4}$

Fourthly, mental states and acts or their contents, it is claimed, represent (conceptually) their satisfaction conditions. Do mental states and acts represent their correctness conditions? This is a question which needs to be posed and answered for each type of mental act and state which is supposed to have correctness conditions. I shall briefly consider three cases in order to make plausible the view that mental states and attitudes do not represent their correctness conditions.

Consider emotions. Many philosophers have thought that

If $\mathrm{x}$ favours $\mathrm{y}$, then $\mathrm{x}$ believes that $\mathrm{y}$ is valuable,

If $\mathrm{x}$ disfavours $\mathrm{y}$, then $\mathrm{x}$ believes that $\mathrm{y}$ is disvaluable.

Thus Kenny says:

${ }^{4}$ Searle sometimes refers to states of affairs in giving the satisfaction conditions for belief (e.g. Searle 1983: 14). The simplified theory of satisfaction conditions referred to here is assumed to have no use for formal objects. 
It is not, of course, correct to say e.g. that the formal object of envy is another's good tout court: one must say that it is something believed to be good... (Kenny 1963: 193).

But is it not possible to have a pro-attitude towards an object, to admire a gesture or an ankle, for example, without believing it to be valuable, for example, graceful? May emotions not colour nonconceptual content?

Might a creature not undergo certain emotions and lack any value concepts? Might a creature not have emotions based on simple seeing and lack beliefs entirely? In $\S 4$ I shall put forward a view of emotions according to which to undergo an emotion is indeed to stand in an intentional relation to value. But this relation, as we shall see, is not belief nor does it involve any representation (thought) of value.

Consider desire. Is it a condition on desire that whoever desires employs a deontic concept? Considerations very like those adduced against the claim that emotions involve axiological beliefs suggest that desires do not constitutively involve deontic beliefs.

Judgements or beliefs, it has often claimed (by Husserl, Pfänder and Bernard Williams), aim at truth or make a claim to be true. ${ }^{5}$ (In the same spirit one might think that desire aims at oughtness and emotions at value). Does this mean that if one judges that $\mathrm{p}$, then one judges that the proposition that $\mathrm{p}$ is true or that it is true that $\mathrm{p}$ ? But the ensuing regress would not be harmless. Suppose that 'It is raining' and 'That it is raining is true' express the very same thought or proposition or are synonymous. Then to judge that is raining is just to judge that that it is raining is true. But since

That it is raining is true because it is raining

our two sentences cannot express the very same thought or be synonymous.

Are the theory of satisfaction conditions and the theory of correctness conditions rival (albeit partial) accounts of intentionality? It is obvious that the thesis that beliefs have satisfaction conditions and the thesis that they have correctness conditions are not incompatible. And the same is true of desires. Nevertheless it seems that emotions and

\footnotetext{
${ }^{5}$ See Engel 2005, especially the rejection of the 'intentional interpretation of truth directedness' at $\S 5$.
} 
preferences have correctness conditions but no satisfaction conditions. It is true that, if emotions and preferences were definable in terms of beliefs and desires, ${ }^{6}$ then it might be possible to show that emotions and preferences do indeed have satisfaction conditions, combinations of the satisfactions conditions of the belief-desire combinations which constitute them. But emotions and preferences are a sui generis category of mental states. Beliefs and desires are propositional states but some emotions are not propositional (scorn, admiration, hate); preference is sometimes propositional sometimes it is the preference for one person over another. Desires are future-directed but some emotions are past-directed (regret). It is therefore very difficult to see what satisfaction conditions for emotions might look like. If this is right, then the theory of intentionality in terms of correctness conditions enjoys the advantage of greater generality over the theory of intentionality in terms of satisfaction conditions.

There is one final striking difference between correctness and satisfaction conditions. The former but not the latter are widely held to be problematic. Correctness conditions refer to entities the existence of which has been roundly rejected by naturalists and by nominalists - propositions and states of affairs. Correctness conditions employ predicates to ascribe properties which have often been considered suspect - value, oughtness. Indeed much twentieth century philosophy has been marked by scepticism about formal objects and properties. Thus philosophers have argued not only that there are no propositions or facts (obtaining states of affairs) but also that 'It is raining' and 'The proposition that it is raining is true' say the very same thing. Similarly, it has been argued that value-ascriptions and normascriptions have no truth-values and that probability can be dispensed with in favour of frequency.

There is also an objection to one particular type of correctness condition, the conditions for judgement (belief, conviction, certainty). Mention of propositions or states of affairs in the correctness conditions for judgements, the objection goes, is superfluous. The only correctness condition we need is:

$\mathrm{x}$ judges that $\mathrm{p} \rightarrow(\mathrm{x}$ judges correctly that $\mathrm{p}$ iff $\mathrm{p})$

\footnotetext{
${ }^{6}$ Cf. Searle 1983: 31-36.
} 
In other words, the satisfaction condition for judgement is just its correctness condition.

How should a friend of correctness conditions react to the many different objections I lumped together under the claim that correctness conditions are problematic? To the objections that there are no propositions or states of affairs, no values and no norms? To the objection that some or all correctness conditions have no truth values? To the claim that correctness conditions for judgment and belief can be given without mentioning states of affairs or propositions?

A philosopher who intends to provide a philosophy of intentionality and thinks that an account of the intentionality of attitudes, acts and states which can miss their mark can be given in terms of correctness conditions must in any case provide a complementary account of the intentionality of knowledge. Suppose that a plausible account of the intentionality of knowledge could be shown to entail that there are facts, values, norms, probabilities etc. Were that the case our philosopher would be able to kill two birds with one stone. He would have an account of the two main types of intentionality and his account of the intentionality of knowledge would give him the very best of reasons for holding that correctness conditions are unproblematic.

What would such an account of the intentionality of knowledge look like? Is such an account plausible? In $\S 3$ I argue that knowledge that $p$ involves a relation to facts. In $\S 4$ I identify the most plausible version of the view that there is knowledge of values.

\section{Knowledge \& facts}

Is knowledge knowledge of facts? Is knowledge that $p$ knowledge of facts, understood in some suitably non-anaemic way? Russell, Vendler (1967), Angelika Kratzer (2000) and Keith Hossack (2007) give affirmative answers to this question. The perhaps more popular, negative, answer is given by Ramsey (1931) and Timothy Williamson (2000). The conception of facts which is shared by friends and enemies of the view that knowledge that $p$ is knowledge of facts is not the view that facts are true truth-bearers, for example, propositions. The shared conception is one of two more robust accounts of facts. According to the first robust account a fact is just an obtaining state of affairs. According to the second robust account, a fact is just a sui generis type of entity in which objects exemplify properties or stand in 
relations. Each of the two robust accounts claims that facts contain objects and properties whereas propositions contain only concepts. In what follows, I shall assume that the first robust account of facts is the right account. ${ }^{7}$

As far as I can tell, reflection on the concept of knowledge that $p$ has not come up with any decisive argument in favour of the view that knowledge that $\mathrm{p}$ is knowledge of facts. There is nevertheless the possibility that types of knowledge other than knowledge that $\mathrm{p}$ constitutively involve an intentional relation to facts and the possibility that reflection on the relations between knowledge that $\mathrm{p}$ and other types of knowledge might lead us to the conclusion that knowledge that $\mathrm{p}$ does after all involve an intentional relation to facts.

Is knowledge that $p$ the only type of knowledge? No. We can distinguish at least four distinct kinds of knowledge. Knowledge is propositional or non-propositional, episodic or non-episodic. In distinguishing between propositional and non-propositional knowledge I have in mind only the distinction between what makes true knowledge ascriptions of the form ' $x$ knows that p' and what makes true ascriptions of the form ' $x$ knows $y$ '. Knowledge that $p$ is propositional and non-episodic; it is either a relational state ${ }^{8}$ or a disposition or constitutively involves an intentional relation. Knowledge that $\mathrm{p}$ is the type of knowledge which dominates contemporary epistemology. But there are at least three other types of knowledge.

There is coming to know that $\mathrm{p}$ or apprehending that $\mathrm{p}$ (erkennen, dass $p$ ), which is propositional and episodic. There is no established or happy English translation of 'erkennen' unless, like some anglophone epistemologists long ago, we talk of an 'act of knowing that'. There is acquaintance, which is non-propositional and non-episodic ('I have known her for years'). And there is coming to be acquainted with (kennenlernen, Kenntnisnahme) someone or something, which is nonpropositional and episodic. This is what might be called making the non-social acquaintance of something or someone.

\footnotetext{
${ }^{7}$ On these three accounts of facts, see Correia \& Mulligan 2007.

${ }^{8}$ For the view that such a relational state is a trope cf. Mulligan \& Smith 1986, Smith 1984 . For the view that it is a non-trope, cf. Williamson 2000. I now believe that knowledge that $\mathrm{p}$ is what I call a functorial and so formal state and no relation. But this complication plays no role in what follows.
} 
How do the four types of knowledge hang together? One very plausible view is that apprehension typically marks the beginning of the state or disposition which is knowledge that p. And that coming to be acquainted with someone or something typically marks the beginning of the state or disposition of being acquainted with that person or thing. On this view, epistemic episodes are more fundamental than epistemic states or dispositions. This view is supported by the observation that we can always ask with respect to any claim to know that $\mathrm{p}$ or any claim to know someone 'How do you know that p?', 'How do you know her?' Questions of this type ${ }^{9}$ make little sense with respect to belief claims:

*How does she believe that $\mathrm{p}$ ?

Answers to the question 'How (cf. 'unde', 'woher') does x know that $\mathrm{p}$ ?' specify the putative source of $\mathrm{x}$ 's knowledge that $\mathrm{p}$. And this source is what is apprehended in the episode of apprehending that p. Answers to the 'How does $\mathrm{x}$ know $\mathrm{y}$ ?' question specify the putative source of x's knowledge of $y$. And this source is what is apprehended in the episode of coming to be acquainted with $\mathrm{y}$.

Let us look first at the most basic case, making the acquaintance of something or someone, episodic knowledge by acquaintance. Is seeing (hearing, touching) someone or something enough to constitute episodic acquaintance? Answers to this question will depend on the account of seeing employed. Suppose, with Dretske, that

$\mathrm{x}$ simply sees $\mathrm{y}$ iff $\mathrm{y}$ is visually differentiated for $\mathrm{x}$

and that if $\mathrm{x}$ simply sees $\mathrm{y}$ and $\mathrm{y}=\mathrm{z}$, then $\mathrm{x}$ simply sees z. Does simple seeing so conceived suffice for making the acquaintance of someone or something? Suppose a young child glimpses out of the corner of her eye a fat man, who is in fact the President. She has then seen the President. Has she become acquainted (in a non-social way) with the President? Does she enjoy epistemic contact with the President? Most of us, I suspect, would give a negative answer to this question. What further condition, then, must be satisfied by simple seeing if it is to count as coming to be acquainted with?

The relevant condition, I suggest, is identification:

${ }^{9}$ Cf. Wittgenstein 1969 §550; Austin 1961: 46; Reiner 1934: 39. 
If $\mathrm{x}$ comes to be visually acquainted with $\mathrm{y}$, then $\mathrm{x}$ sees $\mathrm{y}$ at $\mathrm{t}_{1}$ and then at $\mathrm{t}_{2}$ and sees $\mathrm{y}$ at $\mathrm{t}_{2}$ as the same object.

Seeing things and people as the same, identification, is a phenomenon investigated in psychology under the name of 'object constancy'. Object constancy typically occurs in visual (tactile, auditive) perception along with different types of property constancy, colour constancy, shape constancy etc.

Identification is a mental act which has correctness conditions: $\mathrm{x}$ correctly identifies $\mathrm{y}$ and $\mathrm{z}$ only if $\mathrm{y}=\mathrm{z}$. Such identification may but need not take the form of a judgement. Simple seeing has no correctness conditions; it is an intentional relation we stand in to things and processes. Coming to be visually acquainted with something has no correctness conditions either. But it involves identification, which does have correctness conditions. What we simply see are substances, states, processes and events. Episodic visual acquaintance is acquaintance with objects and properties. It is based on a relation to substances, states, processes and events.

This account of episodic acquaintance provides in all essentials the model for the account to be given of apprehending that p. Simple seeing of things and persons stands to episodic visual acquaintance as seeing that stands to episodic visual apprehension. Suppose Sam sees that Maria is sad. 'See that' is factive, just as 'see' is veridical. Is seeing that $\mathrm{p}$ coming to know that $\mathrm{p}$ ? Just as the fact that Sam sees Maria does not make it true that he thereby makes her acquaintance, so seeing that Maria is sad is not knowledge that she is sad. What do we need to add to seeing that $p$ to obtain visual apprehension that $p$ ? The missing ingredient, as before, is identification:

Sam sees that Maria is sad at $t_{1}$ and then at $t_{2}$ and identifies what he sees at $\mathrm{t}_{1}$ and at $\mathrm{t}_{2}$

But how should this be understood? One bad answer is

*Sam identifies what he sees at $t_{1}$, that Maria is sad, and what he sees at $\mathrm{t}_{2}$, that Maria is sad

This is a bad answer because

*That Maria is sad = that Maria is sad, 
like all instances of

$$
\text { *That } \mathrm{p}=\text { that } \mathrm{q} \text {, }
$$

is unacceptable. All instances of

The fact that $p=$ the fact that $q$,

on the other hand, are well-formed. This suggests that identification should be understood as follows:

Sam identifies the fact that Maria is sad, which he perceives at $t_{1}$, and the fact that Maria is sad, which he perceives at $t_{2}$

Identification is a mental act (a 'synthetic' mental act), unlike the identity predicate or concept. Some identifications are identity judgements. But this is not always the case. When it is not the case, identification typically provides us with good reason to form identity judgements. Similarly, one can identify facts without identifying them as facts. Whether it is a judgement or not identification has, as already noted, correctness conditions.

Suppose Sam is asked whether Maria is sad. Motivated by the desire to reply to the question and the desire to know whether she is sad, he observes her. As before, the identification theory will not claim that

*Sam identifies that Maria is sad, what Sam sees, and that Maria is sad, what Sam refers to.

But rather that

Sam identifies the fact that Maria is sad, which he perceives, and the fact that Maria is sad, which he refers to.

The theory of apprehending that $\mathrm{p}$ as identification might be called the theory of 'fact constancy' by analogy with the theory of object constancy in the area of visual acquaintance with things and persons. The identification theory of apprehension has implications which not all philosophers will find equally acceptable. For example, that to apprehend that $\mathrm{p}$ by inferring validly from known premises to $\mathrm{p}$ involves going through the inference at least twice. And, another example, that coming to know that $p$ through testimony requires a double-take. 
Visual apprehension, like episodic visual acquaintance, is based on a relation. Episodic visual acquaintance is based on the relation of simple seeing. Visual apprehension is based on perceptions of facts not merely on seeing that. Episodic visual acquaintance and visual apprehension are types of knowledge. Are they relations? No. They are complex mental acts and are partly relational and partly nonrelational. The identifications which are constitutive of each type of knowledge can go wrong. They are therefore not relations. But each type of knowledge involves a relation. Thus even those cases of visual acquaintance and visual apprehension which involve judgements differ fundamentally from the case where one judges truly and for good reason on the basis of visual information that $\mathrm{p}$. For such judgements are not relations and do not involve relations.

What is the relation between visual apprehension that $p$ and knowledge that $\mathrm{p}$ ? The answer will depend in part on what we say about the relation between belief and knowledge that $\mathrm{p}$. We have seen that to apprehend that $p$ is not to judge truly that $p$ and for the judgement to be justified. A number of impressive arguments have recently been marshalled against the parallel claim that knowledge that $\mathrm{p}$ is true, justified belief (Williamson 2000). An argument to the same conclusion in the spirit of the foregoing runs as follows. If knowledge that $\mathrm{p}$ were a type of belief, however qualified, it would be possible to ask, with respect to any knowledge claim: 'Why do you know that p'? But, as we have seen, this is not possible. This argument is not, however, conclusive since it might be argued that it is the qualifications of belief which are supposed to constitute knowledge which make it inappropriate to ask the 'why' question.

Two better objections to the view that knowledge is a type of belief have to do with the nature of belief. Firstly, belief (like conviction) but not knowledge comes in degrees. Secondly, belief (like conviction) is either positive or negative. I shall concentrate in what follows on the second objection.

Negative belief that $p$ is not the same thing as positive belief that not-p. Negative belief is disbelief. Belief and disbelief are polar opposites. But knowledge that $\mathrm{p}$ does not have this property. Knowledge has a contradictory opposite, ignorance, and contrary opposites, error 
and illusion. But, unlike belief, knowledge does not come in two kinds, positive and negative. ${ }^{10}$

One argument against the view that coming to know that $\mathrm{p}$ is to judge truly and for good reason that $\mathrm{p}$ relies on a putative similarity between judgement and belief. There is a view of judging according to which it comes in two polarly opposed kinds: positive judging or acceptance and denial or rejection ${ }^{11}$ just as belief comes in two polarly opposed kinds. If this view of judgment is right, then coming to know that $\mathrm{p}$ is never a type of judging. But if Bolzano, Husserl and (perhaps) Frege are right, judging does not come in two polarly kinds: to reject $\mathrm{p}$ is just to judge that not-p. I shall assume here that they are right.

What, then, is the relation between knowledge that $p$, apprehension that $\mathrm{p}$, judgment and belief? Consider

If $\mathrm{x}$ apprehends that $\mathrm{p}$, then $\mathrm{x}$ believes that $\mathrm{p}$.

This is clearly false. Belief is a reaction to, for example, what is (apparently) apprehended when we (apparently) apprehend that $\mathrm{p} .{ }^{12}$ That it is a reaction follows from the fact that it comes in two varieties, positive belief and negative belief (disbelief). Reactions and responses (which manifest intentionality) to phenomena of different sorts may be more

${ }^{10}$ The claim that belief comes in two kinds, positive and negative, is compatible with different views about the ontology of belief. Suppose belief is a disposition and, unlike its categorical basis, not any kind of state. Then to believe that $\mathrm{p}$ is to be disposed to accept $\mathrm{p}$ and to reject not-p. Suppose that belief is a state but no disposition. Then it is either a state of positive belief or a state of negative belief. Presumably, anyone in such a state, for example, the state of disbelief that $\mathrm{p}$, will be disposed to accept not-p and to reject $p$ because of his doxastic state. A third view has it that belief is both a disposition and a state. Finally, there is the view that some beliefs are dispositions but not states and some are states but not dispositions. Perhaps the most plausible candidates for belief states which are not dispositions are beliefs which are (a) important for us, in particular evaluative beliefs, and (b) are continually being tried, tested and reinforced. Sam, for example, is one of those people who continually refer to the European Union as 'the Belgian Empire.' His attitude towards what he takes to be pervasive EU rhetoric is one of strong disbelief. One objection to the view that Sam's disbelief could be a state is that psychological phenomena are episodic. But perhaps Sam's disbelief is one state albeit a scattered state. After all, some substances are spatially scattered.

${ }^{11}$ Cf. Rumfitt 2000.

${ }^{12}$ To believe, Augustine says, is 'cum assensione cogitare' (de praed. sanct. 2 5). 
or less well entrenched, likely or typical. But it is always a contingent matter whether or not a reaction of a certain kind to phenomena of certain other kinds occurs. Often, but not always, we respond doxastically to seeing something or seeing that p. Often, but not always, we respond doxastically to (apparently) apprehending that $\mathrm{p}$.

That we do so react is essential to the state of knowing that $p$. That is why

If $\mathrm{x}$ knows that $\mathrm{p}$, then $\mathrm{x}$ believes that $\mathrm{p}$.

What should we say about

If $\mathrm{x}$ apprehends that $\mathrm{p}$, then $\mathrm{x}$ judges?

This, I argued above, is false since identification of a fact one perceives in one way with a fact perceived in another way need not involve judgement. Nevertheless identification may and often does take the form of a judgement. Apprehension that $\mathrm{p}$ which involves an identity judgement consists of perceptions of a fact and an identity judgement which is correct. Since perception of facts, like simple seeing and simple seeing that, is veridical, apprehension that $p$ is based on a relation to a fact.

If the foregoing is correct, then knowledge that $\mathrm{p}$ has its source in apprehension. Knowledge that $p$ is not knowledge of facts. Apprehension is not apprehension of facts. But perception of facts is constitutive of apprehension. And apprehension that $p$ brings knowledge that $\mathrm{p}$ into being. But that this is so will only be apparent to us if we trace knowledge that $p$ back to its roots, if we ask how we know that $p$. Thus the theory of apprehending that $p$ in terms of identification seems to give the friend of correctness conditions three things he needs: the beginnings of an account of the intentionality of knowledge; reason to think that the reference to obtaining states of affairs or facts in the correctness conditions for belief is neither superfluous nor problematic; an account of the way the intentionality of belief, judgement and knowledge that $\mathrm{p}$ hang together.

\section{Knowledge \& values}

Perhaps the most problematic family of correctness conditions in $\S 2$ is the group of correctness conditions for emotions, wishes, preferences 
and desires. For these conditions are dominated by axiological and deontic predicates and functors. And sentences dominated by such predicates and functors are widely held to have no truth-values. Even philosophers who are prepared to allow that such sentences have truth values often reject one claim made by the friend of correctness conditions. Thus consider again

(1) $\mathrm{x}$ regrets that $\mathrm{p} \rightarrow$ ( $\mathrm{x}$ correctly regrets that $\mathrm{p}$ iff it is regrettable that $\mathrm{p}$ );

(2) If $x$ correctly regrets that $p$, then ( $x$ correctly regrets that $p$ because it is regrettable that $\mathrm{p}$ ).

A friend of correctness conditions who thinks that these provide a partial account of the intentionality of one type of state or attitude, regret, endorses both (1) and (2). But (1) might be combined with the denial of (2) and endorsement of

(3) If it is regrettable that $\mathrm{p}$, then (it is regrettable that $\mathrm{p}$ because ( $\mathrm{x}$ regrets that $\mathrm{p} \rightarrow \mathrm{x}$ correctly regrets that $\mathrm{p})$ ).

(1) and (3) yield one version of what are sometimes called 'neosentimentalist' or 'buck-passing' accounts of what it is to be valuable. According to this version, if something is valuable this is because a proattitude towards it would be correct; if something is sublime, this is because a mixture of awe and something like fear would be correct; if it is shameful that $p$, this is because being ashamed that $p$ would be correct. It is not the most popular version of such theories. The more popular versions do not typically appeal to the correctness of emotions but rather to appropriate emotions, to justified emotions, to permissible emotions or to emotions we have undefeated reasons to feel. ${ }^{13}$

A friend of (1) and (2) (like a friend of (1) and (3)) owes us an account of the intentionality of knowledge of values and norms. Is there any plausible such account which will enable him to claim that the correctness conditions for emotions, desires, wishes and preferences have truth-values? And to claim against the neo-sentimentalist that (2) is to be preferred to (3)? And to specify the nature of the relation between knowledge of values, on the one hand, and desires, emotions, wishes and preferences, on the other hand?

${ }^{13}$ Cf. Rabinowicz \& Rønnow-Rasmussen 2004, Skorupski this volume, Scanlon 1998, Mulligan 1998. 
As far as I can see, the main theories of what it is to have knowledge of values are the following. There is a type of intuitionism which claims that we have intuitive knowledge of values but which says nothing about the nature of this type of intuition. Moore sometimes endorses such a position. Then there is the view which combines the following three claims: (a) we are acquainted with values and know that certain objects are valuable; (b) such acquaintance and knowledge are merely special cases of perceptual acquaintance or intellectual knowledge differing from the more familiar cases only in having unusual objects; (c) acquaintance and knowledge of these kinds are the only form of epistemic contact we have with values. ${ }^{14} \mathrm{~A}$ third type of theory has it that we have affective knowledge of values. A fourth that it is desires rather than affective phenomena which may constitute knowledge of values. Clearly, a philosopher who thinks that we have affective or 'conative' knowledge of values may also hold that we have intellectual axiological knowledge that.

One version of the view that there is affective knowledge of values is the view that affects may 'disclose' values. Such a view has been put forward by Mark Johnston (2001). Another view has it that emotions may disclose values. Such a view has been defended by Christine Tappolet (2000). The view that desires may constitute knowledge of values has been defended by Graham Oddie (2005).

I shall first formulate what I take to be the general form of these or related claims. I shall then formulate some objections to such claims and put forward an alternative. Consider first the view that emotions or affects — favouring — can amount to knowledge of values:

(4) $\mathrm{x}$ is affectively acquainted with the value of $\mathrm{y}$ iff $\operatorname{Val}(\mathrm{y}) \& \mathrm{x}$ appropriately favours $y$;

(5) $\mathrm{x}$ affectively knows that it is valuable that $\mathrm{p}$ iff $\mathrm{Val}(\mathrm{p})$ \& $\mathrm{x}$ appropriately favours that $\mathrm{p}$.

Similarly, we may formulate the view that desires can give us knowledge of values as follows:

(6) $x$ 'desideratively' knows that it is valuable that $p$ iff $\operatorname{Val}(\mathrm{p}) \& \mathrm{x}$ appropriately desires that $\mathrm{p}$.

\footnotetext{
${ }^{14}$ Cf. Thomas 2006: 215, 51.
} 
The first thing to notice about (4)-(6) is their similarity to

(7) $\mathrm{x}$ knows that $\mathrm{p}$ iff $\mathrm{p} \& \mathrm{x}$ justifiably believes that $\mathrm{p}$.

Thus appropriate favouring or desire plays the same role in (4)-(6) as justifiable belief in (7). And the first clause on the right hand side of (7) plays the same role as the first clause on the right hand side of (4), (5) and (6). Perhaps, then, there are objections to (4)-(6) which resemble the objections to (7) above.

One striking feature of affects and emotions is that they often have positive or negative valence. Another is that if an emotion or an affect has a valence, there is often an emotion or affect which is its polar opposite. Being pleased (respect, liking, happiness) has positive valence and a polar opposite, being displeased (scorn, disliking, unhappiness). But surprise has no valence and so can have no polar opposite and enjoyment has a positive valence but no polar opposite. Now knowledge in all its manifestations has no valence and no polar opposite. That is one reason for thinking that emotions and affects cannot constitute knowledge.

There is a second reason for rejecting the view that emotions and affects can yield knowledge. Emotions and affects are reactions, affective reactions. Indeed having a valence suffices to make a state a reaction. States of opposed valence or 'sign' constitute opposed reactions. That is why so many psychological theories consider an action-tendency to be essential to many types of emotions and affects. But knowledge is no reaction. So emotions and affects can never yield knowledge.

Very similar reasons can be advanced against the view that desires may constitute knowledge. Desires (like wishing, wanting, willing and striving) come in two kinds, positive and negative. There is the positive desire that $\mathrm{p}$ and the striving to realise $\mathrm{p}$ but there is also negative desire, negative willing, aversion, shunning (and Widerstreben). Knowledge is not like that.

I suggested in $\S 3$ that belief is a reaction, ${ }^{15}$ that reactions which are intentional states are reactions to something, and that belief is a reaction to, for example, what we apprehend or apparently apprehend. If emotions, desires and affects are reactions and states or attitudes which

\footnotetext{
${ }^{15}$ Are beliefs reactions in the same sense in which emotions are reactions? Cf.: 'The concepts of believing, expecting, hoping are less distantly related (artfremd) to one another than they are to the concept of thinking' (Wittgenstein 1968 \$574).
} 
enjoy intentionality, then we might expect that they, too, are reactions to what is known or apprehended or apparently known or apprehended. But what kind of knowledge could be such that emotions, desires and affects are reactions to its (apparent) deliverances?

An ideal candidate for the role of affective knowledge of value, it is now clear, should satisfy five desiderata. It should not be any sort of reaction and should have no valence and so should not be any sort of emotion, affect or desire. But it should be an affective state or episode. Finally, it should make true a psychological ascription which is veridical or factive. Is there any such thing?

Suppose that Maria is walking down the street and observes a scene in which bread is being distributed unequally to equally needy children. She is struck, as we say, by the injustice of the situation. She has felt the injustice of the situation Perhaps she reacts with indignation. Perhaps she is suffering from indignation fatigue and feels no emotion whatsoever. We are often struck by the elegance of a gesture or the grace of someone's gait, by the rudeness of a remark, by the beauty of a building. Typically experience of value prompts affective reactions, admiration, annoyance, pleasure. That is one reason why it is a mistake to think that experience of value, feeling value, is an affective reaction. Another reason is that although feeling value is an affective phenomenon it has no valence, it is neither positive nor negative, and hence no polar opposite.

Experience of value seems to be very common. Of course, if axiological nihilism is correct, if nothing is a value and nothing has value, then there is no experience of value, only experience as of value. But if ordinary language and experience are taken at face value we are all the time experiencing (dis)value and comparative value. Noncognitivism - axiological and deontic sentences have no truth-values — is difficult to reconcile with many entrenched assumptions. But the claim that what seem to be affective experiences of value are always merely experiences as of value is even more difficult to swallow. The theory of value has suffered from over-concentration on the arguments for and against cognitivism and on the arguments for and against unnatural values and value-properties. The different semantic and metaphysical options can come to look very different if we bear in mind experience of and the experience as of value. Consider, for example, the possibility that only affective value-experience can explain how value-predicates can have any meaning. Neglect of valueexperience also has consequences for substantive ethical and political 
questions. Consider the justification of tolerance. It is one thing to appeal to the fact that different people hold different and often incompatible axiological beliefs. It is quite another to appeal in addition to the fact that we are all in different ways value-blind or, more exactly, insensitive to different types of value; and to the fact that sensitivity to one type of value often makes one insensitive to other types of value.

'Feel' in the sentence 'Maria felt the injustice of the situation' is veridical. If Maria felt the injustice of the situation, then the situation was unjust. If she is struck by the beauty of the building, it is beautiful. Maria's indignation is a reaction either to a felt disvalue, the injustice of the situation or to a merely apparently felt value. In the latter case she is the victim of an illusion. Her admiration of the elegance of Giorgio's gait is a reaction to a felt, positive value or it is a reaction to an apparently felt value. ${ }^{16}$ Above I objected to the claim that

If $\mathrm{x}$ favours $\mathrm{y}$, then $\mathrm{x}$ believes that $\mathrm{y}$ is valuable.

We now have a more plausible alternative:

If $\mathrm{x}$ favours $\mathrm{y}$, then $\mathrm{x}$ feels the value of $\mathrm{y}$ or $\mathrm{x}$ merely seems to feel the value of $\mathrm{y}$ or $\mathrm{x}$ believes $\mathrm{y}$ to be valuable.

Is feeling value an exception to the principle that all knowledge involves identification? No. Values are felt more or less clearly, more or less fully and transitions along these two dimensions involve identification. Aesthetic experience is perhaps the clearest example of the phenomenon of continuously feeling the same value as the same under different modes of presentation. Just as we distinguished between simple seeing and episodic visual acquaintance, so too, we should distinguish between (a) feeling value which is no form of knowledge but rather the analogue of simple seeing and perception and (b) the case where feeling value does constitute knowledge because it involves identification.

The claim that affective knowledge consists at bottom of feeling values and disvalues is, I have argued, superior to theories according to which emotions, affects or desires can yield knowledge. If axio-

\footnotetext{
${ }^{16}$ Some emotions are factives. If Sam regrets that $p$, then $p$. But it is not true that if Sam regrets that $p$, then it is regrettable that $p$.
} 
logical nihilism is false, this claim is, I suggest, the best available approach in the epistemology of values. For it is not only preferable to other theories of affective knowledge and to the idea that desires yield knowledge, it is also preferable to any epistemology the neosentimentalist can come up with.

Suppose with the neo-sentimentalist that being valuable is understood in terms of appropriate emotions or good, undefeated reasons to feel emotions. What, then, would knowledge of the value of an object amount to? The neo-sentimentalist account of what it is to be valuable does not allow one to infer what a neo-sentimentalist account of the knowledge of value would look like. And I have not come across any developed neo-sentimentalist account of the knowledge of value (later than that given by Brentano). But presumably a neo-sentimentalist must hold that we sometimes have knowledge of the appropriateness of an emotion. And in the most basic cases this could only be knowledge that an emotion is appropriate, that there are undefeated reasons to feel an emotion. But if we have knowledge of values it is extremely implausible to think that such knowledge consists only of knowledge that, a knowledge by description which has no anchorage in any knowledge by acquaintance. On one common and plausible view, knowledge that $p$ cannot motivate; even axiological knowledge, knowledge that it is valuable that $p$, is an intellectual state and, like all such states, cannot motivate. Feeling (dis)values, however, is no intellectual state and can motivate. ${ }^{17}$ Finally, it seems that neo-sentimentalism cannot do justice to the fact that the very best reason one could have for feeling, for scorn, admiration etc. is knowledge of the value of the material or proper object of the emotion. ${ }^{18}$

\section{Knowledge vs reactions to what is (apparently) known}

How, then, do the intentionality of knowledge and the intentionality of states and attitudes which can go wrong hang together?

Our answer runs as follows. We have distinguished three types of intentional states and acts: (1) acts and states such beliefs, judgments

${ }^{17}$ Closely related to the distinction between emotions and feeling value is the distinction in neuro- and affective science between emotions and motivational saliency; cf. Berridge \& Robinson 2003.

${ }^{18}$ Cf. Mulligan 2008. 
and emotions which have correctness conditions; (2) acts which are genuinely relational — seeing things, seeing that $\mathrm{p}$, perception of facts - but which are not types of knowledge; (3) five types of knowledge - episodic acquaintance, enduring acquaintance, apprehension that $\mathrm{p}$, knowledge that $\mathrm{p}$ and feeling value.

Knowledge ascriptions, like ascriptions of relational acts, are factive. Intentional relational acts are essential parts of knowledge. Beliefs and emotions are reactions. Part of what it means to say that belief and emotions are intentional states and attitudes is given by specifying their correctness conditions. Another part of what it means to say that they are intentional is given by an account of their material or proper objects, an account about which I have said nothing. Correctness conditions for judgements and beliefs mention states of affairs and predicate the formal property of obtaining of states of affairs. Correctness conditions for emotions mention the material objects of these emotions and predicate formal value properties of these.

The intentionality of beliefs and emotions is triply dependent on the intentionality of knowledge or on the intentionality of relational acts and states. First, beliefs are reactions to what is known or to what seems to be known or to what is the case or to what seems to be the case. Sam judges or believes that Maria is sad on the basis of his acquaintance with the fact that she is sad or on the basis of what seems to be acquaintance with this fact or on the basis of seeing that she is sad or on the basis of seeming to see that that she is sad. Emotions, on the other hand, are reactions to (apparent) non-intellectual, affective knowledge or (apparent) intellectual knowledge of the exemplification of value. Secondly, the correctness conditions of judgements, beliefs and emotions tell us what would be known if these states and acts were reactions to knowledge of the right kind. Finally, if we had no relational contact with facts and values, we would have no right to mention states of affairs or predicate value in correctness conditions or, indeed, anywhere else.

One consequence of the theory of intentionality sketched here is that although the intentionality of many states is explained in part in normative terms ('correctness') and part of the intentionality of knowledge is explained in normative terms (the correctness conditions for identifications), there is nothing normative about the most 
basic types of intentional relations: simple seeing of things and persons, perception of facts and feeling value. ${ }^{19}$

Kevin Mulligan

Départment de Philosophie, Faculté des Lettres Université de Genève

2 , rue de la Candolle

CH 1211 Genève, Switzerland kevin.mulligan@lettres.unige.ch

\section{References}

Austin, J. L. 1961. Other Minds. In Philosophical Papers. Oxford: Clarendon Press, 44-84.

Berridge, K. C. \& Robinson, T. E. 2003. Parsing Reward. Trends in Neuroscience 26, 9: 507-513.

Correia, F. \& Mulligan, K. 2007. Facts. Stanford Encyclopedia of Philosophy, $<$ http://plato.stanford.edu/entries/facts/>.

Engel, P. 2005. Truth and the Aim of Belief. Laws and Models in Science, ed. D. Gillies, 77-97.

Hossack, K. 2007. The Metaphysics of Knowledge. Oxford: Oxford University Press.

Johnston, M. 2001. The Authority of Affect. Philosophy and Phenomenological Research 63(1): 181-214.

Kenny, A. 1963. Action, Emotion, and Will, London: Routledge.

Kratzer, A. 2001. Facts: Particulars or Information Units. Linguistics and Philosophy 25, 5-6: 655-670.

${ }^{19}$ History. The view that the intentionality of many types of states and attitudes can be partially specified in terms of correctness conditions goes back to Husserl. The view that knowledge arises through identification is also Husserlian. The idea that we can feel positive and negative values goes back to Reinach and indeed to Hutcheson and to Kant in his celtic (sometimes misleadingly called his pre-critical) period. This idea together with the claim that emotions are reactions is defended by Scheler and von Hildebrand. The view that belief (but not judgement) comes in two polarly opposed kinds is defended by Reinach. The view that propositional judgement and belief comes in two polarly opposed kinds is defended by Meinong. For details, see Mulligan 2004, 2004a, 2006. Thanks to Wlodek Rabinowicz, who did not know what he was reacting to, to Toni Rønnow-Rasmussen, who did, and to Philipp Keller who saw through what he was reacting to; to Graham Oddie, Barry Smith, Fabrice Teroni, John Skorupski, Christian Beyer, Fabian Dorsch, Olivier Massin and Teresa Marques and also to Philip Gerrans for putting me on to Berridge \& Robinson 2003. My paper was written under the generous auspices of the Swiss NCCR in affective sciences and the FNS project on properties and relations. 
Mulligan, K. \& Smith, B. 1986. A Relational Theory of the Act. Topoi 5/2: $115-130$.

Mulligan, K. 1998. From Appropriate Emotions to Values. Secondary Qualities Generalized, ed. P. Menzies. The Monist 84, 1: 161-188.

Mulligan, K. 2004. Essence and Modality. The Quintessence of Husserl's Theory. In M. Siebel \& M. Textor, eds., Semantik und Ontologie. Beiträge zur philosophischen Forschung. Frankfurt: Ontos Verlag, 387-418.

Mulligan, K. 2004a. Husserl on the 'Logics' of Valuing, Values and Norms. Fenomenologia della Ragion Pratica. L'Etica di Edmund Husserl, eds. B. Centi \& G. Gigliotti, 177-225, Naples: Bibliopolis.

Mulligan, K. 2006. Facts, Formal Objects and Ontology. Modes of Existence. Papers in Ontology and Philosophical Logic, eds. Andrea Bottani \& Richard Davies. Frankfurt: ontos verlag, 31-46.

Mulligan, K. 2008. On Being Struck by Value. Wohin mit den Gefühlen? Emotionen im Kontext, ed. Barbara Merkel, mentis-Verlag, forthcoming.

Oddie, G. 2005. Value, Desire and Reality. Oxford: Oxford University Press.

Rabinowicz, W. \& Rønnow-Rasmussen, T. 2004. The Strike of the Demon: On Fitting Pro-Attitudes and Value. Ethics 114: 391-423.

Ramsey, F. 1931. Facts and Propositions. In The Foundations of Mathematics. London: Kegan Paul.

Reiner, H. 1934. Das Phänomen des Glaubens. Halle: Niemeyer.

Rumfitt, I. 2000. Yes and No. Mind 109: 781-823.

Scanlon, T. M. 1998. What we Owe to Each Other. Cambridge, MA: Harvard University Press.

Searle, J. 1983. Intentionality. An Essay in the Philosophy of Mind. Cambridge: Cambridge University Press.

Smith, B. 1984. Acta cum fundamentis in re. Dialectica 38: 157-178.

Tappolet, C. 2000. Emotions et Valeurs. Paris: Presses Universitaires de France.

Teroni, F. 2007. Emotions and Formal Objects. Dialectica Vol. 61, Fasc. 3: 395-416.

Thomas, A. 2006. Value and Context. The Nature of Moral and Political Knowledge. Oxford: Clarendon Press.

Vendler, Z. 1967. Linguistics in Philosophy. Ithaca: Cornell University Press.

Williamson, T. 2000. Knowledge and its Limits, Oxford: Oxford University Press.

Wittgenstein, L. 1968. Philosophical Investigations. Oxford: Blackwell.

Wittgenstein, L. 1969. On Certainty. New York: Harper. 